\title{
Estimating relative risk of within-lake aquatic plant invasion using combined measures of recreational boater movement and habitat suitability
}

Marion E Wittmann, Bruce E Kendall, Christopher L Jerde, Lars W. J. Anderson

Effective monitoring, prevention and impact mitigation of nonindigenous aquatic species relies upon the ability to predict dispersal pathways and receiving habitats with the greatest risk of establishment. To examine mechanisms affecting species establishment within a large lake, we combined observations of recreational boater movements with empirical measurements of habitat suitability represented by nearshore wave energy to assess the relative risk of Eurasian watermilfoil (Myriophyllum spicatum) establishment. The model was evaluated using information from a 17 year (1995-2012) sequence of $M$. spicatum presence and absence monitoring. M. spicatum presence was not specifically correlated with recreational boater movements; however its establishment appears to be limited by wave action in Lake Tahoe. Of the sites in the "High" establishment risk category $(n=37), 54 \%$ had current or historical infestations, which included 8 of the 10 sites with the highest RR. Of the 11 sites in the "Medium" establishment risk category, 5 had current or historical M. spicatum populations. Most (76\%) of the sites in the "Low" establishment risk category were observed in locations with higher wave action. Four sites that received zero boater visits from infested locations were occupied by $M$. spicatum. This suggests that the boater survey either represents incomplete coverage of boater movement, or other processes, such as the movement of propagules by surface currents or introductions from external sources are important to the establishment of this species. This study showed the combination of habitat specific and dispersal data in a relative risk framework can potentially reduce uncertainty in estimates of invasion risk. 
2 Marion E.Wittmann ${ }^{1,2,3}$, Bruce E. Kendall ${ }^{1}$, Christopher L. Jerde ${ }^{3}$, Lars W.J. Anderson ${ }^{4}$

$3 \quad{ }^{1}$ Bren School of Environmental Science and Management, University of California, Santa Barbara, CA

$4 \quad 93106-5131$

$5 \quad{ }^{2}$ Department of Biological Sciences, University of Notre Dame, Notre Dame IN 46556

$6 \quad{ }^{3}$ Department of Biology, University of Nevada, Reno NV 89557

$7 \quad{ }^{4}$ US Department of Agriculture, Agricultural Research Service (Retired), Waterweed Solutions, Pt.

8 Reyes, CA

9

10 Correspondence: Marion E. Wittmann, Email: mwittmann@gmail.com, Phone: 8054488259 


\section{Introduction}

12 Predicting establishment for nonindigenous aquatic species (NAS) remains one of the greatest

13 challenges for invasion ecologists yet is a key element for effective ecosystem monitoring and

14 management. Assessing the risk of establishment requires an understanding of the number of

15 individuals introduced to a particular area over time (i.e., propagule or colonization pressure) and

16 characteristics of the receiving environment (Lockwood, Cassey \& Blackburn, 2005). Where propagule

17 pressure is high and habitat is suitable for a species to survive and reproduce, the risk of establishment

18 and growth is substantial (VonHolle \& Simberloff, 2005; Drake \& Jerde, 2009).

20 Propagule pressure is difficult to measure directly for most aquatic species. Within aquatic ecosystems,

21 boat movement as well as dispersal through natural currents contribute to the propagation and spread of

22 aquatic species (Mosisch \& Arthington, 1998; Beletsky et al., 2007; Clarke Murray, Pakhomov \&

23 Therriault, 2011). Both fragments and established populations of invasive seaweed (Caulerpa taxifolia)

24 have been found in greater abundances in estuaries with high rates of recreational boating compared to 25 areas with less recreational boating (West et al., 2009). Hull fouling associated with commercial or 26 recreational activities is a well-known dispersal vector for both marine and freshwater introductions

27 (Johnson \& Carlton, 1996; Mineur, Johnson \& Maggs, 2008; Clarke Murray, Pakhomov \& Therriault, 28 2011). The exchange and discharge of ballast water has also been shown to increase secondary spread

29 rates within the Great Lakes (Carlton, 1985; Sieracki, Bossenbroek \& Faisal, 2013). Finally, advective

30 movement via surface currents have also been found to increase the spread of both fish and

31 invertebrate species within large lakes (Beletsky et al., 2007; Hoyer et al., 2014). While a lot of

32 information exists regarding the spread of species within aquatic systems, the specific relationship

33 between human-mediated and natural dispersal of species is largely unknown. 
35 The focus of the current study was Eurasian watermilfoil (Myriophyllum spicatum) a freshwater

36 macrophyte species native to Europe, Asia and Northern Africa and introduced to North America in the

37 1940's (Couch \& Nelson, 1985). In North America, M. spicatum impacts native species (Boylen,

38 Eichler \& Madsen, 1999) and has unwanted effects on ecosystem services (Eiswerth, Donaldson \&

39 Johnson, 2000; Halstead et al., 2003; CAST, 2014). Widespread dispersal occurred after its initial

40 introduction in North America, as M. spicatum was a popular aquarium and trade species, and also

41 planted into lakes and streams — spreading through water currents to connected waterways (Aiken et

42 al., 1979; Madsen, Eichler \& Boylen, 1988). Recreational boats have also been implicated as the main

43 overland dispersal vector for freshwater aquatic plants, including M. spicatum (Johnstone, Coffey \&

44 Howard-Williams, 1985; Rothlisberger et al., 2010). However, other mechanisms of dispersion, such

45 as endo- or ectozoochoric transport by birds have also been observed for aquatic plants (Figuerola \&

46 Green, 2002). M. spicatum is estimated to have established in this study system, Lake Tahoe, CA-NV

47 [USA], in the 1970's (Kim \& Rejmankova, 2001; Anderson, 2003). By 2012 M. spicatum had spread

48 to over 20 sites in water depths up to $5 \mathrm{~m}$, covering approximately $0.34 \mathrm{~km}^{2}$ overall in the lake (Fig. 1).

50 The dispersion of M. spicatum within Lake Tahoe is a complex process with multiple interacting

51 components. In Lake Tahoe, M. spicatum propagates primarily through vegetative fragments and not

52 through seed germination (Walter, 2000). As most M. spicatum populations in Lake Tahoe are located

53 within marinas or other nearshore protected zones, fragments are created when boat propellers cut the

54 plant or when mechanical harvesting occurs (a non-chemical control activity in the lake).

55 Fragmentation also occurs naturally in Lake Tahoe due to the plant's phenology (e.g., autofragment

56 production) (Barrat-Segretain \& Bornette, 2000; Walter, 2000). An important factor of M. spicatum

57 success as a colonizer is its ability to survive and produce roots up to six weeks after fragmentation

58 (Jerde et al., 2012; Mcalarnen et al., 2012). 
60 Long distance dispersal within the lake then depends on transport mechanisms (e.g., entrainment on

61 boats or boating equipment, advective transport through water currents, biologically based transport via

62 birds or other species) between areas where $M$. spicatum is established and areas where it is not. This

63 may include the movement of fragments across open waters or laterally within nearshore regions.

64

65 Once viable fragments reach a novel habitat, various environmental conditions such as temperature,

66 sediment composition and energetics of surface waves may determine if new M. spicatum colonies will

67 become established (Smith \& Barko, 1990; Martin \& Valentine, 2012). M. spicatum photosynthesizes

68 and grows over a wide temperature range $\left(15-35^{\circ} \mathrm{C}\right)$ and can successfully overwinter in icy conditions

69 (Smith \& Barko, 1990). It grows best on fine textured inorganic sediments (Barko \& Smart, 1986) but

70 can be the dominant species over a wide range of sediment particle distributions (e.g., 15 - $100 \%$ sand)

71 and sediment and/or water column nutrient concentrations (Smith \& Barko, 1990; Madsen, 1999). The

72 intensity of wave action and water movement are also important factors for $M$. spicatum establishment.

73 Water flow may stimulate abundance at low to moderate velocities, but reduce growth at higher

74 velocities (Schutten \& Davy, 2000; Madsen et al., 2001; Martin \& Valentine, 2012). Wave heights of

75 0.1-0.3 m have been shown to cause M. spicatum breakage, although not to the extent to impact

76 viability of the plant (Stewart et al., 1997). As invasion success is dependent on multiple factors (e.g.,

77 transport, propagule pressure, habitat suitability), combining assessments of these factors, when

78 possible, should improve estimates of risks for further spread and establishment.

80 Because it is difficult to observe an accurate relationship between propagule pressure and invasion risk

81 when habitat suitability is different across sites, one approach is to include relative measures of

82 individual survival and propagule pressure to develop a prediction framework (Herborg et al., 2007; 
83 Jerde \& Lewis, 2007). For example, gravity models have used recreational boater movements to

84 estimate relative abundance of human-transported NAS (Schneider, Ellis \& Cummings, 1998;

85 Bossenbroek, Kraft \& Nekola, 2001; Muirhead \& Macisaac, 2005), but have failed to incorporate the

86 characteristics of the receiving habitat into predictions of establishment likelihood. Relative measures

87 of species survival have been estimated using habitat matching models that compare species origins

88 and putative destinations on a global scale (Drake \& Bossenbroek, 2004; Herborg et al., 2007). We

89 seek to combine measures of propagule pressure and habitat suitability within a lake, in order to

90 establish a framework that can be used for managers tasked with minimizing the impact of invasion

91 that is already ongoing.

92

93 This study assesses the relative risk of invasion spread within a single freshwater lake (Lake Tahoe) by

94 examining two components of M. spicatum establishment: the physical properties of recipient habitats,

95 and human-mediated propagule pressure via recreational boating trips between these habitats. We used

96 direct measures of boater visitation frequency to approximate propagule pressure. Intensity of wave

97 action at nearshore locations in Lake Tahoe was used to categorize relative risk into three categories

98 (high, medium, low) and identify areas most vulnerable to recreational boat-mediated introduction of

99 M. spicatum. We hypothesized that if wave height and propagule pressure are working in concert to

100 determine establishment, then more sites in the high-risk category should be invaded than in the

101 medium and low risk categories. Within a category, if propagule pressure is driving establishment,

102 then sites with relatively more risk should be more likely to have been invaded.

103

\section{Materials and Methods}

\section{Site description}


106 Lake Tahoe is a large (surface area: $497 \mathrm{~km}^{2}$, max depth $501 \mathrm{~m}$ ) oligotrophic lake located in the Sierra

107 Nevada between California and Nevada USA at a subalpine elevation of $1898 \mathrm{~m}$. Measurements of

108 water clarity in Lake Tahoe have shown average Secchi disk depths of $20 \mathrm{~m}$ (TERC, 2014) and light

109 measurements of $1 \%$ light levels have been recorded to nearly 50

$110 \mathrm{~m}$ (Rose et al., 2009). Since 1980, the volume-weighted annual average concentration of nitrate-

111 nitrogen was 13-19 $\mu \mathrm{g} / \mathrm{L}$ and that of total phosphorus was 1.5-4.0 $\mu \mathrm{g} / \mathrm{L}$ (TERC, 2014). Annual average

112 chlorophyll $a$ in this same time period was 0.7-1.1 $\mu \mathrm{g} \mathrm{Chl} a$ /L (Heyvaert et al., 2013). The Tahoe

113 basin's granitic geology, the lake's large volume $\left(150 \mathrm{~km}^{3}\right)$ and small watershed $\left(800 \mathrm{~km}^{2}\right)$ explain the

114 low nutrient concentrations and primary productivity rates (Goldman, 1988). In recent decades, Lake

115 Tahoe has been subject to a number of environmental stressors such as development, atmospheric

116 deposition, and other impacts related to human-use or climate related change. Lake Tahoe is subject to

117 intense recreational pressure, with over 3 million people visiting and over 20,000 trailered boats

118 launched into the lake each year.

120 Previously Lake Tahoe's benthic zone was dominated by a number of Characeae, mosses, liverworts 121 and filamentous algae species, which have been observed at depths up to $400 \mathrm{~m}$ (Frantz \& Cordone, 122 1967; Caires et al., 2013).The native macrophytes Andean milfoil (M. quitense), Canadian waterweed 123 (Elodea canadensis), coontail (Ceratophyllum demersum), Richardson's pondweed (Potamogeton 124 richardsonii) and leafy pondweed (Potamogeton foliosus) are found in Lake Tahoe. With the exception 125 of one marina location (the "Tahoe Keys" which was built into a dredged wetland site), where $C$.

126 demersum has been the most abundant macrophyte species at water depths $<2 \mathrm{~m}$, the nonnative $M$.

127 spicatum has dominated the submersed aquatic plant community at water depths $<5 \mathrm{~m}$ since the mid-

128 1990's. In the early 2000's curlyleaf pondweed (P. crispus) established in the southern region of Lake

129 Tahoe, and populations have rapidly expanded along the southern shore. Where P. crispus has 
130 established, it also dominates the native nearshore macrophyte community, and in some cases, has

131 replaced M. spicatum populations, particularly in protected embayments, constructed marinas and

132 disturbed (dredged) areas.

133

134 Distribution of Eurasian watermilfoil populations and recreational boater survey

135 Lake surveys to determine Eurasian watermilfoil distribution, 1995 - 2012

136 Whole-lake surveys for M. spicatum presence and absence were carried out annually in Lake Tahoe

137 from 1995 to 1997 and in 2000, 2003, 2006 and 2012. A two to three person boat crew

138 circumnavigated the nearshore zone, including marinas and other embayments, and visually inspected

139 below the water surface for aquatic macrophytes from the vessel. If vegetation was spotted, a double-

140 edged rake was thrown into the vegetation or divers snorkeled underwater to retrieve samples for

141 species identification in the laboratory (Anderson \& Spencer, 1996). In 2012 divers snorkeled or used

142 SCUBA amongst vegetation to make in situ identification (K. Boyd, pers. comm. 2014).

\section{Recreational boater survey}

145 To determine the pathways of Lake Tahoe boaters, individuals $(\mathrm{N}=778)$ were interviewed at public and 146 private Lake Tahoe boat launches during the summer periods of 2005 and 2006 on 30 dates from July-

147 September 2005 and June-September 2006. Of the 30 dates, 14 were weekdays, and 16 were weekends

148 and/or holidays. On any given date, interviews were conducted for an 8-10 hour period between 8

149 A.M. and 6:00 P.M. The interview consisted of ten questions and lasted approximately 5-10 minutes.

150 Questions relevant to this study pertained to the boater's launch origination and trips made between

151 nearshore zones within the lake. The set of originations and destinations were defined by responses

152 given by boaters, with as few as 1 and as many as 5 origination and destination combinations per

153 boater collected. Each origination and destination combination was counted as one trip, and when the 
154 origination was from a site that contained M. spicatum, that trip constituted one potential propagule.

155 This measurement of visitation to each boater destination site from a set of infested locations is

156 referred to as $B$. A point biserial correlation coefficient was computed to assess the relationship

157 between the presence of M. spicatum (including extirpated populations) and recreational boater

158 visitation.

159

160 Habitat characterization

161 Wave action

162 To gauge the amount of energy or wave action in nearshore zones in Lake Tahoe, change in vertical

163 pressure was measured using submersed depth pressure sensors (RBR DR-1050, accuracy $\pm 0.05 \%$ ) at

16413 locations around the lake (Fig. 1). The sensor locations were distributed around all sides of the lake

165 and were chosen to capture nearshore wave action caused by prevailing wind patterns (Schladow et al.,

166 2012). Each sensor was placed at approximately the same depth (3 $\mathrm{m})$ and set at a 1 second sampling

167 interval for a period of 14 days from July through September 2006. Because there were only four

168 sensors and a limited field period, measurements were taken continuously at the northern end of the

169 lake (site CBI) with a single logger, and three other loggers were moved every 14-day sampling period.

170 The continuous measurements taken at CBI were used to estimate significant wave heights $\left(\mathrm{H}_{\mathrm{s}}\right.$, or the

171 highest $1 / 3$ of all waves measured) during the weeks for which a site did not have a logger present.

173 Change in surface water depth was calculated using the following pressure to wave height conversions: 174

175 pressure $=p-$ Atmospheric pressure (dBar), Equation 1 
177 where $\mathrm{p}=$ pressure reading from the sensor (dBar), and atmospheric pressure was the calibration for

178 high elevation conditions at Lake Tahoe (1897 m). The conversion of pressure into depth was

179 described by the following equation:

180

$181 \operatorname{depth}(m)=\frac{\text { pressure }}{g \rho}$,

Equation 2

182

183 where $\mathrm{g}$ is a gravitational constant $\left(0.980665 \mathrm{~m} \mathrm{~s}^{-2}\right)$ and $\rho\left(1.0 \mathrm{~g} \mathrm{~mL}^{-3}\right)$ is water density. To characterize

184 the lake state in the various nearshore areas, significant wave heights $\left(\mathrm{H}_{\mathrm{s}}\right)$, maximum wave heights

$185\left(\mathrm{H}_{\max }\right)$, and the root mean square wave heights $\left(\mathrm{H}_{\mathrm{rms}}\right)$ were determined for all sites and represented the

186 temporal variability over the entirety of the sampling period for each site (Dean \& Dalrymple, 1991).

187 For each of the locations identified by recreational boaters, wave height characterizations were

188 assigned based on proximity to the nearest pressure sensor measurement.

\section{Water column and sediment characteristics}

191 Preliminary measurements at 23 sites around the lake of nearshore water column characteristics $(\operatorname{chl} a$,

192 dissolved oxygen, $\mathrm{pH}$, temperature, and turbidity) and sediment nutrient and mineral concentrations

$193\left(\mathrm{NH}_{4}, \mathrm{NO}_{3}\right.$, Ortho-P, TP, Ca, Mn, Fe) indicated no meaningful variation in these habitat features

194 between sites; thus these variables were removed from the habitat assessment.

\section{Estimating Relative Risk}

197 We used relative measures of boater visitation from an infested site (B), to assess invasion risk of $M$.

198 spicatum within Lake Tahoe. After Jerde and Lewis (2007), we calculated the relative ratio $(R R)$ of $B$

199 for invasion of location $\mathrm{X}$ relative to $B$ for invasion of location $\mathrm{Y}$, where location $\mathrm{Y}$ was the location 
200 with the lowest (non-zero) B, for each site. Simply, RR was the proportion of boater visitation $\left(B_{\mathrm{X}}\right)$ for

201 a site, relative to the $\mathrm{B}_{\mathrm{Y}}$ for the least visited site:

$203 R R=\frac{B_{X}}{B_{Y}}$

Equation 3

As M. spicatum establishment has been shown to be limited by wave action (Schutten \& Davy, 2000;

Martin \& Valentine, 2012), we further refined the relative risk evaluation based on empirical

measurements of wave height as an indicator of habitat suitability. This serves to improve the ability to

prioritize specific sites for surveillance by categorizing relative risk by high, medium and low

establishment risk. Specifically, these establishment risk categories were divided into three groups

according to their maximum wave height $\left(\mathrm{H}_{\max }\right)$ as measured during the June - August, 2006 period in

211 Lake Tahoe: "High establishment risk" ( $<0.2 \mathrm{~m})$ "Medium establishment risk" (0.2 - $0.3 \mathrm{~m})$ or "Low

212 establishment risk" (>0.3 m). Relative risk comparisons between sites in different establishment risk

213 categories were not valid owing to the unknown relationship between specific values $\mathrm{H}_{\max }$ and

214 establishment of any particular M. spicatum fragment.

216 We used a chi-squared test to determine whether there were differences between the frequencies of

217 invasion (e.g., realized establishments of M. spicatum) for the "High", "Medium", and "Low"

218 establishment risk categories. If there were no statistically significant differences between these

219 categories, then we would proceed to test the explanatory power of the relative risk across all sites.

220 However, if there were statistically significant differences between these categories, then logistic

221 regression would be performed on each category (High, Medium, and Low) with number of boater

222 visits as the explanatory variable. All analyses were carried out using R (v 2.13.0). 


\section{RESULTS}

\section{Eurasian watermilfoil survey}

226 In 1995, there were 13 nearshore sites in Lake Tahoe with M. spicatum presence. The number of sites

227 with M. spicatum presence slowly increased, with 17 sites observed in 2000, 22 sites in 2003 and 26

228 sites in 2005. In 2011 there were 23 sites with M. spicatum presence, and in 2012 the number of

229 occupied sites declined again, to 17 (Fig. 2), with a total coverage of approximately $0.35 \mathrm{~km}^{2}$, or $0.07 \%$

230 of Lake Tahoe's area. The decrease in number of sites in 2011 and 2012 relative to previous years is a

231 result of management (bottom barriers, dredging) and/or other causes of extirpation of localized

232 populations (K. Boyd pers. comm. 2014).

234 Recreational boater survey

235 There were a total of 65 sites named by the 778 interviewed recreational boaters as destinations within

236 Lake Tahoe (Fig. 2). There were 1756 origination-destination trips and the most visited sites included

237 Emerald Bay (a popular scenic destination; $N=273$ trips) and Tahoe Keys (a destination with

238 amenities e.g., gas, food, launch ramp; $\mathrm{N}=214$ ). Both of these sites have established M. spicatum

239 populations; however the Tahoe Keys infestation is much greater, with dense stands reaching the water 240 surface and directly adjacent to moored boats and in boat traffic lanes. There were four sites $(23 \%$ of

241 those with infestations) where boater visitation was 0 , yet populations of $M$. spicatum have been

242 present in those locations for a majority of the invasion record. Other popular sites visited were those

243 with amenities (restaurants, gas stations) or are known as popular places to recreate. There were 769

244 origination-destination trips from locations with M. spicatum. There was no significant correlation

245 between the presence of $M$. spicatum (including extirpated populations) and recreational boater

246 visitation $\left(\mathrm{r}_{\mathrm{pb}}=0.22, \mathrm{df}=63, \mathrm{p}=0.08\right)$. 
249 Similar to Lake Tahoe nearshore wave heights recorded during 2008-2009 summer and winter periods 250 (which included one winter storm) (Schladow et al., 2012), wave heights measured in this study ranged 251 from 0 to $0.5 \mathrm{~m}$ (Table 1). In general, the eastern shore of Lake Tahoe receives more wave action than 252 the west shore of the lake (Schladow et al., 2012). Pressure sensor measurements also confirmed this to 253 be true during the summer of 2006; the highest maximum wave heights recorded were on the east or 254 northeast shore at CR, CBI, RHP, SH and ZPH (Table 1). Of 13 sites measured, five sites had an $\mathrm{H}_{\max }$ $255<0.2$, four sites were between 0.2 and 0.3 , three were 0.3 or greater and one sensor malfunctioned 256 during its deployment at location DLB and was not included. This breakdown was used to define the 257 establishment risk categories (e.g., $\mathrm{H}_{\max }<0.2=$ "High", $0.2<\mathrm{H}_{\max }<0.3=$ "Medium" and $\mathrm{H}_{\max }>0.3=$ 258 "Low").

There was a significant association between establishment risk category and frequency of $M$. spicatum 261 presence $\left(\chi^{2}=8.66, \mathrm{df}=2, p=0.013\right.$; Table 2$)$. Of the 37 sites in the "High" establishment risk 262 category, 54\% have current or historical infestations of $M$. spicatum, including 8 of the 10 sites with 263 the highest RR in this risk category. Of sites in the "High" establishment risk category, 35\% had $B=0$, 264 indicating no visitation by boaters originating from sites with M. spicatum. Of the 11 sites in the 265 "Medium" establishment risk category, 5 have either current or historical M. spicatum populations and 2669 sites have $\mathrm{B}>0$. Most of the sites in the "Low" establishment risk category are located on the east or 267 northeast shore (e.g., the locations with higher wave action), and only two of them have current or 268 historical M. spicatum populations. However, both of these populations are in protected areas (e.g., 269 behind rock cribs or within a marina), and were not exposed to wave action of the other 15 sites. Thus, 
270 these locations may be considered as high energy (e.g., low establishment risk) environments that are

271 overcome by protective barriers.

273 There was only adequate power for logistic regression analyses (e.g., enough observations of $M$.

274 spicatum presence) within the high establishment risk category, which indicated that RR was not a

275 reasonable predictor of $M$. spicatum presence $(\mathrm{z}=0.903, \mathrm{p}=0.367, \mathrm{df}=36)$. When risk categorizations

276 are removed and RR was considered over all sites, it was also not a reasonable predictor of $M$.

277 spicatum presence $(\mathrm{z}=1.386, \mathrm{p}=0.166, \mathrm{df}=64)$.

\section{Discussion}

280 Similar to previous assessments of M. spicatum establishment at the landscape scale (Buchan \&

281 Padilla, 1999; Rothlisberger \& Lodge, 2011), we have found that propagule pressure as represented by

282 recreational boater visitation was not a significant explanatory factor of its presence within a lake.

283 Further, characteristics of the receiving habitat, e.g., wave action, were found to be a limiting factor for

284 M. spicatum establishment in Lake Tahoe. However, the extent to which boater movement is a singular 285 useful predictor of M. spicatum in Lake Tahoe is not clear. While recreational boats may certainly play 286 a role in the release and movement of $M$. spicatum, the plant's distribution may be more dependent on 287 alternative dispersal vectors (e.g. wind-driven surface currents, transport by birds), variation in 288 temporal scales, or habitat limitations.

290 There were four sites (23\% of those with infestations) where boater visitation was 0 , yet populations of 291 M. spicatum have been present in those locations for a majority of the invasion record. This indicates 292 that either the boater survey data did not accurately represent visitation, or that another physical 293 process such as the movement of propagules by surface currents is important. For example, boaters 
294 may not necessarily deliver a propagule to other nearshore sites, but rather boats may break $M$.

295 spicatum stems with propellers and create fragments which are then liberated out into the lake, where

296 they may be susceptible to advective transport by water currents to other nearshore zones (Anderson, 297 2003).

298

299 However, it is possible that recreational boating played an important role in the direct delivery of 300 invasive plants through entrainment on boats or equipment (Rothlisberger et al., 2010) to popular and 301 scenic sites such as Emerald Bay. Emerald bay is one of the few non-marina sites that contain $M$. 302 spicatum in the lake. It is also the most highly visited area by boaters in Lake Tahoe; over $70 \%$ of 303 surveyed boaters visited this location. The predominant south shore winds and water flows move 304 eastward (Schladow et al., 2012), the opposite direction of Emerald Bay from most established M. 305 spicatum populations (see Fig. 1). The abrupt appearance of the recently established non-native 306 species, curlyleaf pondweed, at Emerald Bay suggests that some sort of long distance dispersal 307 mechanism may be supporting the establishment of species in this area. Wave action has been cited as an important factor for M. spicatum growth and establishment in Lake

310 Tahoe and elsewhere (Walter, 2000; Madsen et al., 2001; Martin \& Valentine, 2012). The energetics of

311 highly wavy sites such as $\mathrm{CR}, \mathrm{ZPH}$ and $\mathrm{SH}$ along the eastern shore combined with $M$. spicatum

312 absence (with the exception of locations where there are protective rock cribs or marina structures)

313 supports this notion. Despite the short duration of empirical data collection (e.g., 14 days per probe and

314 a two month overall period) at each site and the interpolation of the measurements, these observations

315 capture the range of multi-year wave heights (including summer and winter storms) both empirically 316 measured (Schladow et al. 2012) and simulated (Smith, 2001) in Lake Tahoe. 
318 Temporal lags associated with the expansion of M. spicatum within Lake Tahoe may also be indicative

319 of why some sites with high relative risk estimates do not have established M. spicatum populations.

320 We propose that these lags may be attributed to the lake's trophic status. First discovered in Lake

321 Tahoe over 60 years ago, M. spicatum is currently established in only 17 locations around the $116 \mathrm{~km}$

322 lake perimeter, with an abundance of potentially suitable (e.g., sandy sediments and protected

323 embayment) habitats remaining unoccupied. Oligotrophic systems, such as Lake Tahoe, often are

324 characterized by low benthic taxon richness (Declerck et al., 2005), which may make these

325 communities less resistant than more diverse communities to species invasions (Stachowicz et al.,

326 2002). Properties of oligotrophic systems that contribute to low taxon richness, such as low nutrient

327 conditions, temperatures or high UV exposure may present similar barriers to somatic growth, spread

328 and establishment for M. spicatum (Tucker et al., 2010).

330 However, Lake Tahoe's benthic community is currently undergoing significant environmental change

331 (Caires et al., 2013), and eutrophication favors the success of colonists (Christie, Fraser \& Nepszy,

332 1972). Indeed, Lake Tahoe has recently experienced increased disturbance through nearshore

333 development, temperature warming, the establishment of other nonindigenous species (e.g., Asian

334 clam, signal crayfish and various warmwater fishes) and losses in water transparency (Goldman, 1988;

335 Frantz \& Cordone, 1996; Chandra et al., 2005; Kamerath, Chandra \& Allen, 2008; Coats, 2010;

336 Wittmann et al., 2012). These stressors are likely to alter ecosystem dynamics that may affect the

337 expansion rates of species such as M. spicatum or P. crispus within the lake. The use of relative risk

338 assessments may be a better predictor in the future, when there are fewer barriers to establishment.

Future directions 
341 There are many unknowns associated with the establishment of species, which often leaves managers

342 having to react to, rather than prevent, new infestations of NAS within ecosystems. Here, we have

343 developed an approach to reduce the uncertainty associated with identifying site-specific establishment

344 risk and the subsequent development of surveillance or other management programs within a lake

345 ecosystem. We propose that this framework can also be applied to a wide range of species over

346 multiple spatial scales in part because of the increased availability of species- or system-specific data.

347 Freely available resources that describe species dispersal pathways (e.g., the 100th Meridian Initiative

348 Recreational boater database, National Ballast Information Clearing House) combined with field

349 measurements of physical or biological data (e.g., NOAA National Climatic Data Center, USGS

350 Nonindigenous Aquatic Species Database) can be compiled to build relative risk assessment utilizing

351 the methods similar to those proposed herein.

353 Acknowledgements

354 We thank F. Davis, J. Fram, S. MacIntyre, (UC Santa Barbara), C. Shade (TRPA), C.R. Goldman, S.

355 Hackley, G. Schladow, C. Strasenburgh and H. Segale (UC Davis), B. Blank and S. Chandra

356 (University of Nevada Reno), and N. Cartwright and K. Boyd (Tahoe Resource Conservation District)

357 for their support of this research. H. Mäemets and an anonymous reviewer provided comments that

358 improved the manuscript.

\section{References}

360 Aiken SG, Newroth R, Wiles I, Received OMW, Control H. 1979. The biology of Canadian weeds. 34 $361 \quad$ Myriophyllum spicatum L. Canadian Journal of Plant Science 59:201-215.

362

Anderson LWJ. 2003. A review of aquatic weed biology and management research conducted by the United States Department of Agriculture - Agricultural Research Service. Pest Management Science 59:801-813.

Anderson L, Spencer DF. 1996. Survey of Lake Tahoe for presence of Eurasian watermilfoil: USDA Agricultural Research Service Aquatic Weed Control Investigations, Annual Report. Davis, CA.

Barko JW, Smart RM. 1986. Sediment-related mechanisms of growth limitation in submersed macrophytes. Ecology 67:1328-1340. 
Barrat-Segretain M, Bornette G. 2000. Regeneration and colonisation abilities of aquatic plant fragments: effect of disturbance seasonality. Hydrobiologia 421:31-39.

Beletsky D, Mason DM, Schwab DJ, Rutherford ES, Janssen J, Clapp DF, Dettmers JM. 2007. Biophysical Model of Larval Yellow Perch Advection and Settlement in Lake Michigan. Journal of Great Lakes Research 33:842-866.

Bossenbroek JM, Kraft CE, Nekola JC. 2001. Prediction of long-distance dispersal using gravity models: Zebra mussel invasion of inland lakes. Ecological Applications 11:1778-1788.

Boylen CW, Eichler LW, Madsen JD. 1999. Loss of native aquatic plant species in a community dominated by Eurasian watermilfoil. Hydrobiologia 415:207-211.

Buchan LAJ, Padilla DK. 1999. Estimating the probability of long-distance overland dispersal of invading aquatic species. Ecological Applications 9:254-265.

Caires AM, Chandra S, Hayford BL, Wittmann ME. 2013. Four decades of change: dramatic loss of zoobenthos in an oligotrophic lake exhibiting gradual eutrophication. Freshwater Science 32:692705.

Carlton JT. 1985. Transoceanic and interoceanic dispersal of coastal marine organisms: the biology of ballast water. Oceanography and Marine Biology 1985:313-371.

CAST. 2014. Benefits of Controlling Nuisance Aquatic Plants and Algae in the United States: Commentary QTA2014-1. Ames, IA.

Chandra S, Vander Zanden MJ, Heyvaert AC, Richards BC, Allen BC, Goldman CR. 2005. The effects of cultural eutrophication on the coupling between pelagic primary producers and benthic consumers. Limnology and Oceanography 50:1368-1376.

Christie W, Fraser J, Nepszy S. 1972. Effects of species introductions on salmonid communities in oligotrophic lakes. Journal of the Fisheries Board of Canada 29:969-973.

Clarke Murray C, Pakhomov EA, Therriault TW. 2011. Recreational boating: A large unregulated vector transporting marine invasive species. Diversity and Distributions 17:1161-1172.

Coats R. 2010. Climate change in the Tahoe basin: Regional trends, impacts and drivers. Climatic Change 102:435-466.

Couch R, Nelson E. 1985. Myriophyllum spicatum in North America. In: Anderson L ed. First International Symposium Watermilfoil and Related Haloragaceae Species. Vicksburg, Mississippi: Aquatic Plant Management Society, 8-18.

Dean RG, Dalrymple RA. 1991. Water Wave Mechanics for Engineers and Scientists. New York, NY: Prentice Hall.

Declerck S, Vandekerkhove J, Johansson L, Muylaert K, Conde-Porcuna JM, Van Der Gucht K, PérezMartínez C, Lauridsen T, Schwenk K, Zwart G et al. 2005. Multi-group biodiversity in shallow lakes along gradients of phosphorus and water plant cover. Ecology 86:1905-1915.

Drake JM, Bossenbroek JM. 2004. The Potential Distribution of Zebra Mussels in the United States. BioScience 54:931.

Drake JM, Jerde CL. 2009. Stochastic models of propagule pressure and establishment. In: Keller R, Lewis M, Lodge D, Shogren J eds. Bioeconomics of invasive species: integrating ecology, economics, policy, and management. Oxford University Press, 82-102.

Eiswerth ME, Donaldson SG, Johnson WS. 2000. Potential Environmental Impacts and Economic Damages of Eurasian Watermilfoil (Myriophyllum spicatum) in Western Nevada and Northeastern California. Weed Science Society of America 14:511-518.

Figuerola J, Green A. 2002. Dispersal of aquatic organisms by waterbirds: a review of past research and priorities for future studies. Freshwater Biology 47:483-494.

Frantz TC, Cordone AJ. 1967. Observations on deepwater plants in Lake Tahoe, California and Nevada. Ecology 48:709-714. 
416 Frantz T, Cordone A. 1996. Observations on the macrobenthos of Lake Tahoe, California-Nevada. :82: $417 \quad 1-41$.

418 Goldman CR. 1988. Primary productivity, nutrients, and transparency during the early onset of eutrophication in ultra-oligotrophic Lake Tahoe, California-Nevada. Limnology and Oceanography 33:1321-1333.

Halstead JM, Michaud J, Hallas-Burt S, Gibbs JP. 2003. Hedonic Analysis of Effects of a Nonnative Invader (Myriophyllum heterophyllum) on New Hampshire (USA) Lakefront Properties. Environmental Management 32:391-398.

Herborg L, Jerde CL, Lodge DM, Ruiz GM, MacIsaac HJ. 2007. Predicting Invasion Risk Using Measures of Introduction Effort and Environmental Niche Models. Ecological Applications 17:663-674.

Heyvaert AC, Reuter JE, Chandra S, Susfalk R, Schladow SG, Hackley S. 2013. Lake Tahoe Nearshore Evaluation and Monitoring Framework. Final Report.

Hoyer AB, Wittmann ME, Chandra S, Schladow SG, Rueda FJ. 2014. A 3D individual-based aquatic transport model for the assessment of the potential dispersal of planktonic larvae of an invasive bivalve. Journal of Environmental Management 145:330-340.

Jerde C, Barnes M, DeBuysser E, Noveroske A, Chadderton L, Lodge D. 2012. Eurasian watermilfoil fitness loss and invasion potential following desiccation during simulated overland transport. Aquatic Invasions 7:135-142.

Jerde CL, Lewis MA. 2007. Waiting for Invasions: A Framework for the Arrival of Nonindigenous Species. The American Naturalist 170:1-9.

Johnson LE, Carlton JT. 1996. Post-establishment spread in large-scale invasions: dispersal mechanisms of the zebra mussel Dreissena polymorpha. Ecology 77:1686-1690.

Johnstone IM, Coffey BT, Howard-Williams C. 1985. The role of recreational boat traffic in interlake dispersal of macrophytes: a New Zealand case study. Journal of Environmental Management 20:263-279.

Kamerath M, Chandra S, Allen B. 2008. Distribution and impacts of warm water invasive fish in Lake Tahoe, USA. Aquatic Invasions 3(1):35-41. Aquatic Invasions 3:35-41.

Kim J, Rejmankova E. 2001. The paleoecological record of human disturbance in wetlands of the Lake Tahoe Basin. Journal of Paleolimnology 25:437-454.

Lockwood JL, Cassey P, Blackburn T. 2005. The role of propagule pressure in explaining species invasions. Trends in ecology evolution 20:223-8.

Madsen JD. 1999. Predicting the invasion of Eurasian watermilfoil into northern lakes.

Madsen JD, Chambers PA, James WF, Koch EW, Westlake DF. 2001. The interaction between water movement, sediment dynamics and submersed macrophytes. Hydrobiologia 444:71-84.

Madsen JD, Eichler LW, Boylen CW. 1988. Vegetative spread of Eurasian watermilfoil in Lake George, New York. Journal of Aquatic Plant Management 26:47-50.

Martin C, Valentine J. 2012. Eurasian milfoil invasion in estuaries: physical disturbance can reduce the proliferation of an aquatic nuisance species. Marine Ecology Progress Series 449:109-119.

Mcalarnen LA, Barnes MA, Jerde CL, Lodge DM. 2012. Simulated overland transport of Eurasian watermilfoil: survival of desiccated plant fragments. Journal of Aquatic PLant Management 50:147-149.

Mineur F, Johnson MP, Maggs CA. 2008. Macroalgal introductions by hull fouling on recreational vessels: Seaweeds and sailors. Environmental Management 42:667-676.

Mosisch TD, Arthington AH. 1998. The impacts of power boating and water skiing on lakes and reservoirs. Lakes \& Reservoirs: Research and Management 3:1-17. 
Muirhead JR, Macisaac HJ. 2005. Development of inland lakes as hubs in an invasion network. Journal of Applied Ecology 42:80-90.

Rose KC, Williamson CE, Schladow SG, Winder M, Oris JT. 2009. Patterns of spatial and temporal variability of UV transparency in Lake Tahoe, California-Nevada. Journal of Geophysical Research: Biogeosciences 114:G00D03.

Rothlisberger JD, Chadderton WL, McNulty J, Lodge DM. 2010. Aquatic Invasive Species Transport via Trailered Boats: What is Being Moved, Who is Moving it, and What Can Be Done. Fisheries 35:121-132.

Rothlisberger JD, Lodge DM. 2011. Limitations of gravity models in predicting the spread of eurasian watermilfoil. Conservation Biology 25:64-72.

Schladow S, Bombardelli F, Reardon K, Moreno P, Hackley S, Forrest AL, Rueda F, Hoyer A, Castro M, Acosta $\mathrm{M}$ et al. 2012. Predicting and managing changes in near-shore water quality: Final Report.

Schneider DW, Ellis CD, Cummings KS. 1998. A transportation model assessment of the risk to native mussel communities from zebra mussel spread. Conservation Biology 12:788-800.

Schutten J, Davy AJ. 2000. Predicting the hydraulic forces on submerged macrophytes from current velocity, biomass and morphology. Oecologia 123:445-452.

Sieracki JL, Bossenbroek JM, Faisal M. 2013. Modeling the secondary spread of viral hemorrhagic septicemia virus (VHSv) by commercial shipping in the Laurentian Great Lakes. Biological Invasions 16:1043-1053.

Smith JM. 2001. Modeling nearshore wave transformation with STWAVE; No. ERDC/CHL CHETN-I64. Vicksburg, Mississippi.

Smith CS, Barko JW. 1990. Ecology of Eurasian watermilfoil. Journal of Aquatic Plant Management 28:55-64.

Stachowicz J, Fried H, Osman R, Whitlatch R. 2002. Biodiversity, Invasion Resistance, and Marine Ecosystem Function: Reconciling Pattern and Process. Ecology 83:2575-2590.

Stewart RM, McFarland DG, Ward DL, Martin SK, Barko JW. 1997. Flume Study Investigation of the Direct Impacts of Navigation-Generated Waves on Submersed Aquatic Macrophytes in the Upper Mississippi River: Technical Report ENV Report 1. Vicksburg, Mississippi.

TERC. 2014. State of the lake report 2013. Tahoe Environmental Research Center, University of California Davis, CA.

Tucker AJ, Williamson CE, Rose KC, Oris JT, Connelly SJ, Olson MH, Mitchell DL. 2010. Ultraviolet radiation affects invasibility of lake ecosystems by warm-water fish. Ecology 91:882-890.

VonHolle B, Simberloff D. 2005. Ecological resistance to biological invasion overwhelmed by propagule pressure. Ecology 86:3212-3218.

Walter KM. 2000. Ecosystem effects of the invasion of Eurasian watermilfoil (Myriophyllum spicatum) at Lake Tahoe, CA-NV. University of California Davis.

West EJ, Davis AR, Barnes PB, Wright JT. 2009. The role of recreational activities in creating fragments of invasive Caulerpa taxifolia. Journal of Experimental Marine Biology and Ecology 376:17-25.

Wittmann ME, Chandra S, Reuter JE, Schladow SG, Allen BC, Webb KJ. 2012. The control of an invasive bivalve, Corbicula fluminea, using gas impermeable benthic barriers in a large natural lake. Environmental Management 49:1163-73. 


\section{Table $\mathbf{1}$ (on next page)}

Wave height measurements

Location and position of pressure sensors in Lake Tahoe to measure nearshore wave heights June - August, 2006. $H_{s}=$ Significant Wave Height, $H_{\max }=$ Maximum Wave Height, $H_{r m s}=$ Root mean square Wave Height, all represented in meters $(m)$. Risk = Category of Eurasian watermilfoil risk of establishment based on $\mathrm{H}_{\max }$; High $<0.2,0.2<$ Medium $<0$. 3, and Low $>0.3 \mathrm{~m}$. 


\begin{tabular}{|l|l|c|c|c|c|c|l|}
\hline \multicolumn{1}{|c|}{ ID } & Location Name & Lat & Long & $\mathrm{H}_{\mathrm{s}}$ & $\mathrm{H}_{\max }$ & $\mathrm{H}_{\mathrm{rms}}$ & Risk \\
\hline BWM & Boatworks Marina & 39.171 & -120.137 & 0.006 & 0.027 & 0.003 & High \\
\hline KBG & Garwoods & 39.225 & -120.083 & 0.004 & 0.031 & 0.002 & High \\
\hline CRM & Camp Richardson & 38.939 & -120.039 & 0.019 & 0.113 & 0.011 & High \\
\hline LFL & Lake Forest Launch & 39.181 & -120.120 & 0.013 & 0.128 & 0.008 & High \\
\hline EPM & Elks Point & 38.984 & -119.957 & 0.020 & 0.181 & 0.012 & High \\
\hline ZPH & Zephyr Cove & 39.007 & -119.950 & 0.027 & 0.208 & 0.017 & Medium \\
\hline RHP & Round Hill Pines & 38.990 & -119.954 & 0.025 & 0.213 & 0.016 & Medium \\
\hline RUB & Rubicon Bay & 39.002 & -120.102 & 0.018 & 0.218 & 0.010 & Medium \\
\hline SPE & Sugar Pine/Ehrman & 39.060 & -120.113 & 0.034 & 0.253 & 0.021 & Medium \\
\hline SH & Sand Harbor & 39.201 & -119.931 & 0.029 & 0.294 & 0.019 & Low \\
\hline CBI & Crystal Bay/Incline & 39.248 & -119.989 & 0.029 & 0.377 & 0.019 & Low \\
\hline CR & Cave Rock & 39.042 & -119.949 & 0.059 & 0.537 & 0.040 & Low \\
\hline
\end{tabular}




\section{Table 2 (on next page)}

Relative risk boater movement table

Proportion of boater visits from sites with Eurasian milfoil (B; Total number of trips from infested locations, $N=769$ ), and $R R(B)$ or Relative Risk based on $B$ for 65 nearshore sites in Lake Tahoe, USA. RR is relative to site differentiation of establishment risk categorization (High, Medium, Low) as determined by measurements of nearshore wave action. ${ }^{*}$ Currently infested with Eurasian milfoil, †Historical infestation of Eurasian milfoil. 
2 High Establishment Risk

3 (Low Wave Action)

\begin{tabular}{lcr} 
Site & B & RR(B) \\
\hline EmeraldBay* & 0.22 & 169 \\
LakeForest & 0.16 & 124 \\
TahoeKeys* & 0.10 & 79 \\
CampRich ${ }^{\dagger}$ & 0.08 & 58 \\
ElDorado* & 0.04 & 27 \\
Sunnyside ${ }^{\dagger}$ & 0.03 & 22 \\
BaldwinBeach ${ }^{\dagger}$ & 0.02 & 15 \\
TahoeCity* & 0.01 & 10 \\
Garwoods & 0.01 & 7 \\
HurricaneBay & 0.00 & 2 \\
KivaBeach* & 0.01 & 5 \\
KingsBeach & 0.01 & 4 \\
SkiRun* & 0.01 & 4 \\
SouthShore* & 0.01 & 4 \\
Stateline* & 0.01 & 4 \\
SkiBeach & 0.00 & 2 \\
TimberCove* & 0.00 & 2 \\
CarnelianBay & 0.00 & 1 \\
Cascade & 0.00 & 1 \\
LarsonsBeach & 0.00 & 1 \\
LesterBeach & 0.00 & 1 \\
PopeBeach* & 0.00 & 1 \\
TahoeMeadows* & 0.00 & 1 \\
TahoeTavern ${ }^{*}$ & 0.00 & 1 \\
AgateBay & 0.00 & 0 \\
Chinquapin & 0.00 & 0 \\
DollarPoint & 0.00 & 0 \\
ElksPointBeach* & 0.00 & 0 \\
HighSierraBoatCo & 0.00 & 0 \\
Lakeland* & 0.00 & 0 \\
NevadaBeach* & 0.00 & 0 \\
SierraBoatCo & 0.00 & 0 \\
SkylandiaBeach & 0.00 & 0 \\
TahoeFlats ${ }^{*}$ & 0.00 & 0 \\
TahoePark ${ }^{*}$ & 0.00 & 0 \\
& 0.00 & 0 \\
Tista & & 0
\end{tabular}

5 Medium Establishment Risk

6 (Medium Wave Action)

\begin{tabular}{lcr} 
Site & B & RR(B) \\
\hline MeeksBay* & 0.05 & 14 \\
ZephyrCove ${ }^{\dagger}$ & 0.04 & 11 \\
RubiconBay & 0.03 & 9 \\
DLBliss & 0.02 & 5 \\
SugarpinePoint & 0.02 & 5 \\
Obexers ${ }^{\dagger}$ & 0.02 & 4 \\
Homewood ${ }^{\dagger}$ & 0.01 & 3 \\
RoundHillPines* & 0.01 & 2 \\
ChambersBeach & 0.00 & 1 \\
MarlaBay & 0.00 & 0 \\
Tahoma & 0.00 & 0
\end{tabular}

7

8 Low Establishment Risk

9 (High Wave Action)

\begin{tabular}{lcr} 
Site & B & $R R(B)$ \\
\hline SandHarbor & 0.04 & 16
\end{tabular}

$\begin{array}{lll}\text { CaveRock } & 0.02 & 6\end{array}$

SkunkHarbor $\quad 0.01 \quad 4$

InclineVillage $\quad 0.01 \quad 2$

Hyatt $\quad 0.00 \quad 1$

SecretHarbor $\quad 0.00 \quad 2$

DeadMansPoint $\quad 0.00 \quad 1$

ThunderbirdLodge $\quad 0.00 \quad 1$

CalNeva $\quad 0 \quad 0$

ChimneaBeach $\quad 0 \quad 0$

CrystalBay* $\quad 0 \quad 0$

GlenBrook $\quad 0 \quad 0$

HiddenBeach $\quad 0 \quad 0$

LoganShoals ${ }^{\dagger} \quad 0 \quad 0$

Lynbrook $\quad 0 \quad 0$

SnakeHarbor $\quad 0 \quad 0$

SpeedboatBeach $\quad 0 \quad 0$ 
1

Study site map figure

Lake Tahoe, CA-NV. Circles indicate Eurasian watermilfoil (Myriophyllum spicatum) presence as of 2012. Crosses indicate wave action measurement sites.

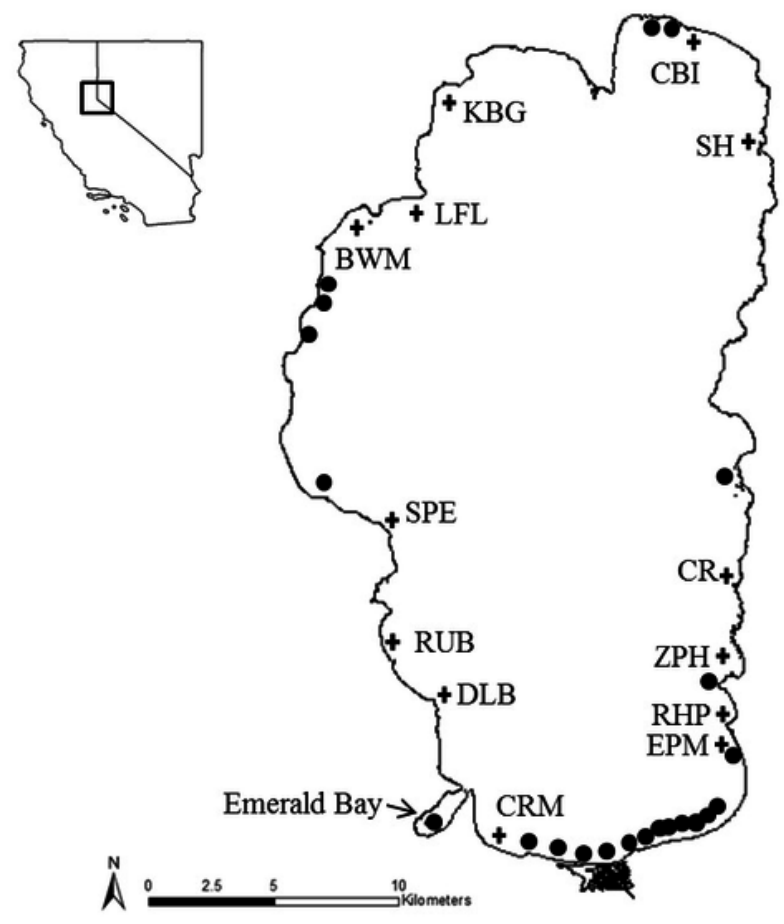


2

Boater visitation and site infestation

Invasion probability as a function of propagule pressure as represented by boater visitation from sites infested with M. spicatum in Lake Tahoe. Black circles indicate M. spicatum presence in 2012.

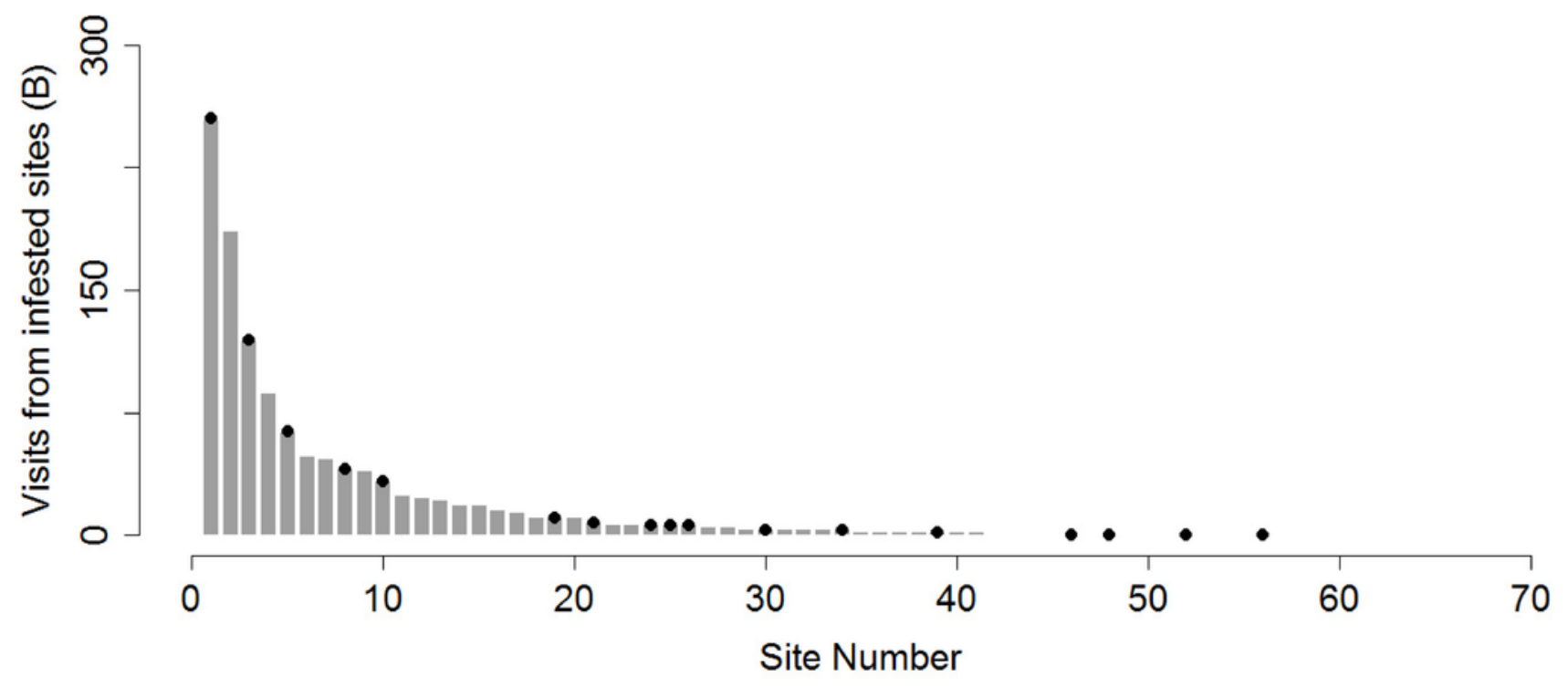

